\title{
ANATOMIA DO LENHO DE CEPHALANTHUS GLABRATUS (SPRENG.) K. SCHUM. (RUBIACEAE)1
}

\author{
ANELISE MARTA SIEGLOCH ${ }^{2}$ JOSÉ NEWTON CARDOSO MARCHIORI ${ }^{3}$ \\ SIDINEI RODRIGUES DOS SANTOS ${ }^{4}$
}

\section{RESUMO}

O lenho de Cephalanthus glabratus (Spreng.) K. Schum. (Rubiaceae) é descrito em seus aspectos microscópicos. A estrutura anatômica é comparada com referências da literatura, sendo especialmente analisada a presença de caracteres anatômicos indicadores de reofilia.

Palavras-chave: anatomia da madeira, Cephalanthus glabratus, plantas reófilas, Rubiaceae.

\section{ABSTRACT}

[Wood anatomy of Cephalanthus glabratus (Spreng.) K. Schum. (Rubiaceae)].

The wood microscopic features of Cephalanthus glabratus (Spreng.) K. Schum. (Rubiaceae) are described. The anatomical structure is checked with literature references, with special interest on the presence of rheophilic features in the wood.

Key words: wood anatomy, Cephalanthus glabratus, rheophilic plants, Rubiaceae.

\section{INTRODUÇÃO}

A família Rubiaceae, uma das mais numerosas das Angiospermas, compreende cerca de 500 gêneros e aproximadamente 7.000 espécies (Joly, 2002) de árvores, arbustos, lianas e ervas, com distribuição cosmopolita e maior diversidade em regiões tropicais e subtropicais (Judd et al., 2009). A maioria das espécies apresenta folhas simples, inteiras, lineares ou ovadas, em filotaxia oposta ou verticilada, e com estípulas interpeciolares muito características (Schultz, 1963). Para a flora sul-rio-grandense, destacam-se os gêneros Amaioua, Bathysa, Cephalanthus, Chomelia, Cordiera, Coussarea,

1 Recebido para publicação em 05-5-2011 e aceito para publicação em 13-6-2011.

2 Acadêmica do Curso de Graduação em Engenharia Florestal, bolsista de iniciação científica (PIBIC-CNPQ), Universidade Federal de Santa Maria, CEP 97105900 , Santa Maria, RS, Brasil. anesiegloch@yahoo.com.br

3 Engenheiro Florestal, Dr. Bolsista de Produtividade em Pesquisa (CNPq - Brasil). Professor Titular do Departamento de Ciências Florestais, Universidade Federal de Santa Maria. marchiori@pq.cnpq.br

${ }^{4}$ Biólogo, M.Sc. Doutorando do Programa de Pós-Graduação em Engenharia Florestal, Universidade Federal de Santa Maria.sthurt.bio@gmail.com
Coutarea, Faramea, Guettarda, Machaonia, Posoqueria, Psycotria, Randia e Rudgea (Sobral et al., 2006).

Nativa no sul do Brasil, Paraguai, Uruguai e nordeste da Argentina (Cabrera \& Zardini, 1978), Cephalantus glabrathus (Spreng.) K. Schum. encontra-se, no Rio Grande do Sul, sobretudo na bacia do rio Uruguai e recebe os nomes comuns de sarandi, sarandi-branco, sarandi-vela (Reitz et al., 1988), sarandi-mole, (Backes \& Nardino, 2001) e sarandi-colorado (Cabrera \& Zardini, 1978). Espécie hidrófila (Lahitte \& Hurrell, 1994), habita terrenos baixos, inundados e margens de rios e arroios (Bacigalupo, 1974). Trata-se de arbusto ou arvoreta de 3-5 m de altura, caducifólio ou de folhagem semipersistente, com folhas lanceoladas (2,5 - 9 × 0,5 - $3 \mathrm{~cm})$, glabras, inteiras, dispostas em verticilos trifoliados; as flores, brancas e com suave perfume de canela, dispõem-se em glomérulos globosos longamente pedunculados. A planta floresce e frutifica na primavera e verão, respectivamente (Brussa \& Grela, 2007). De pequeno porte e fácil propagação vegetativa, Cephalanthus glabratus apresenta bom potencial para obras de Bio- 
engenharia, por ser planta reófila, naturalmente adaptada para suportar a correnteza das águas.

Além de descrever a estrutura microscópica do lenho de Cephalanthus glabratus, o presente estudo também visa a contribuir ao conhecimento anatômico das espécies reófilas nativas no Rio Grande do Sul.

\section{REVISÃO DE LITERATURA}

Para a família Rubiaceae, Metcalfe \& Chalk (1972) relacionam: vasos tipicamente pequenos, médios em alguns gêneros; elementos vasculares de comprimento médio a longo; poros exclusivamente solitários ou em múltiplos radiais de 4 ou mais unidades, raramente com porosidade em anel; placas de perfuração simples; pontoações intervasculares alternas, pequenas a muito pequenas; parênquima apotraqueal, nas espécies com fibras não septadas, e ausente nas com septos, salvo exceções; raios estreitos (1-3 células) e heterogêneos, com 4 ou mais fileiras marginais de células quadradas e eretas, mas até 8-10 células de largura em algumas espécies; fibras muito curtas a moderadamente longas, com septos ou não, providas de pontoações simples ou areoladas; e cristais de sílica e ráfides, presentes em alguns gêneros. Para a família, destacam-se, ainda, os estudos de KoekNoorman (1969a, b; 1970, 1972), KoekNoorman \& Hogeweg (1974), Jansen et al.(1997), Rogers (2005), Patel \& Patel (2011).

Cephalanthus glabratus carece de descrição microscópica detalhada do lenho. Para a espécie, todavia, Koek-Noorman (1970) relaciona, entre outros detalhes estruturais: vasos com mais de $100 \mu \mathrm{m}$ de diâmetro e freqüência superior a $40 / \mathrm{mm}^{2}$; porosidade em anel; fibras com pontoações areoladas, mais freqüentes nas faces tangenciais da parede; raios unisseriados com mais de $1 \mathrm{~mm}$ de altura; parênquima dos tipos paratraqueal e apotraqueal difuso; e presença de células perfuradas em raios.

Para o gênero, Record \& Hess (1943) e Metcalfe \& Chalk (1972) referem: vasos de tamanho médio (100 a $200 \mu \mathrm{m}$ ); porosidade em anel; parênquima vasicêntrico; e raios unisseriados, ocasionalmente com alguns bisseriados. A estes caracteres, Koek-Noorman (1970) agrega a presença de fibrotraqueóides, de poros solitários, de raios estreitos e de parênquima predominantemente apotraqueal.

Sobre a anatomia de espécies reófilas existem escassas referências na literatura. Com base em Phyllanthus sellowianus, Sebastiania schottiana, Salix humboldtiana e Salix x rubens, Denardi (2007) reconheceu uma série de características estruturais associados à "síndrome anatômica de reofilia": vasos pequenos $(<100 \mu \mathrm{m})$, solitários ou em múltiplos radiais, e com paredes de 2,5 - 5,0 $\mu \mathrm{m}$ de espessura; parênquima axial pouco abundante ou ausente; raios estreitos; elementos vasculares e fibras com cerca de 400 e $700 \mu \mathrm{m}$ de comprimento, respectivamente; abundância de fibras gelatinosas; e tecido lenhoso composto por $10-30 \%$ de vasos, $10-$ $20 \%$ de raios, $60-70 \%$ de fibras, e até $5 \%$ de parênquima axial. Tais valores foram confirmados para outras espécies, por Siegloch et al. (2011) e Santos et al. (2011), com exceção da presença de fibras gelatinosas.

\section{MATERIAL E MÉTODOS}

O material investigado consiste de uma amostra de madeira e respectivo material botânico (Marchiori n. 983, 23-01-2009), coletados na orla da mata ciliar do rio Ibicuí, no interior do município de Itaqui, RS.

Para a descrição anatômica da madeira foram confeccionadas lâminas histológicas e de macerado. Para as primeiras, seguiu-se a técnica padrão: os corpos de prova foram amolecidos por fervura em água e seccionados em micrótomo de deslizamento, regulado para a obtenção de cortes com $20 \mu \mathrm{m}$ de espessura. Os cortes foram tingidos com acridina-vermelha, crisoidina e azul-de-astra (Dujardin,1964), desidratados em série alcoólica-ascendente (30\%, $50 \%, 70 \%, 95 \%$, duas vezes álcool absoluto), seguindo-se a passagem por xilol e montagem em lâminas permanentes, com "Entellan". Para as lâminas de macerado, usou-se o método de Jeffrey (Burger \& Richter, 1991), coloração da 
pasta com safranina $1 \%$, e montagem permanente, com a mesma resina acima referida.

A descrição microscópica seguiu as normas do IAWA Committee (1989). Para as percentagens de tecidos, usou-se um contador de laboratório e 600 determinações ao acaso, de acordo com Marchiori (1980). A freqüência de po$\mathrm{ros} / \mathrm{mm}^{2}$ foi obtida de forma indireta, a partir de um quadrado de área conhecida superposto a fotomicrografia de secção transversal da madeira. As medições foram realizadas no Laboratório de Anatomia da Madeira da Universidade Federal de Santa Maria, usando-se microscópio Carl Zeiss dotado de ocular com escala graduada. Nas características quantitativas, os números entre parênteses correspondem aos valores mínimos e máximos observados; o valor que acompanha a média é o desvio padrão. As fotomicrografias foram tomadas em microscópio Olympus cx 40, com câmera digital Olympus Camedia c3000 acoplada ao microscópio, no laboratório de Anatomia da Madeira da Universidade Federal do Paraná, a quem os autores agradecem.

\section{DESCRIÇÃO ANATÔMICA}

Anéis de crescimento distintos, estreitos, marcados pela porosidade semi-difusa e camadas de fibras radialmente estreitas no lenho tardio (Figura 1A).

Vasos: extremamente numerosos $(155 \pm 8,1$ $\left(143,7\right.$ - 162,5) poros $\left./ \mathrm{mm}^{2}\right)$, em porosidade difusa, ocupando $22,8 \pm 3,7 \%$ do volume da madeira. Poros solitários e curtos múltiplos radiais de 2-3 (até 8), muito pequenos (57,2 $\pm 12,5$ $(37,5-87,5) \mu \mathrm{m})$, de paredes finas $(2,3 \pm 0,7$ $(1,2-4,4) \mu \mathrm{m})$ e contorno angular/poligonal (Figura 1A, B). Elementos vasculares de comprimento médio $(464,4 \pm 82,9(320-650) \mu \mathrm{m})$, com placas de perfuração simples, oblíquas, e apêndices em uma ou em ambas as extremidades; espessamentos espiralados, ausentes. Pontoações intervasculares pequenas $(4,9 \pm 0,5$ $(4,1-5,7) \mathrm{m})$, alternas, circulares ou poligonais, ornamentadas, com abertura em fenda inclusa. Pontoações raio-vasculares semelhantes às intervasculares, embora menores $(4,1 \pm 0,3(3,6$ $-4,6) \mu \mathrm{m}$ ) e concentradas na margem de raios.

Parênquima axial: em arranjos apotraqueal difuso e paratraqueal escasso, representando 5,8 $\pm 1,5 \%$ do volume da madeira. Séries parenquimáticas de $2-5$ células e 369,8 \pm 79,9 $(230$ - 525) $\mu \mathrm{m}$ de altura.

Raios: muito numerosos (21,2 \pm 1,9 (19 24) raios/mm), com $1-2$ células de largura, ocupando $30 \pm 2,1 \%$ do volume da madeira. Raios bisseriados de $1164 \pm 461,8$ (480 - 2250) $\mu \mathrm{m}$ de altura, com 20 -30 (46) células; heterogêneos (Figura 1E), reúnem células procumbentes, no corpo central, e células quadradas e eretas, nas margens (Figura $5 \mathrm{C}$ ); as margens, com 2 - 26 células, são invariavelmente mais longas do que o corpo central. Os unisseriados, de 1332,4 $\pm 568,1(380-2300)$ $\mu \mathrm{m}$ de altura e 15 - 30 (49) células (Figura 1E, F), reúnem células quadradas e eretas. Raios fusionados, presentes. Células radiais de paredes disjuntas, escassas. Células perfuradas de raios, freqüentes (Figura 1D). Conteúdo, ausente.

Fibras: compondo $41,3 \pm 5,2 \%$ do volume da madeira; de comprimento médio (1015,2 \pm $72,2(850-1140) \mu \mathrm{m})$, com $24 \pm 2,8(17,5-$ 30) $\mu \mathrm{m}$ de largura e de paredes finas a espessas $5,2 \pm 0,7(3,7-6,2) \mu \mathrm{m}$ (Figura 1B). Fibras gelatinosas, espessamentos espiralados, e traqueídeos, ausentes. Pontoações areoladas com aberturas cruzadas, nas faces radiais e tangenciais da parede.

Outros caracteres: variantes cambiais, tubos laticíferos e taniníferos, canais intercelulares, células oleíferas, células mucilaginosas, estratificação, máculas medulares e inclusões minerais, ausentes.

\section{ANÁLISE DA ESTRUTURA ANATÔMICA}

As características anatômicas observadas no material em estudo concordam com o referido por Metcalfe \& Chalk (1972) para Rubiaceae: poros muito pequenos e numerosos; elementos vasculares médios, com placas de perfurações simples e sem espessamentos espiralados; pontoações intervasculares alternas, ornamen- 

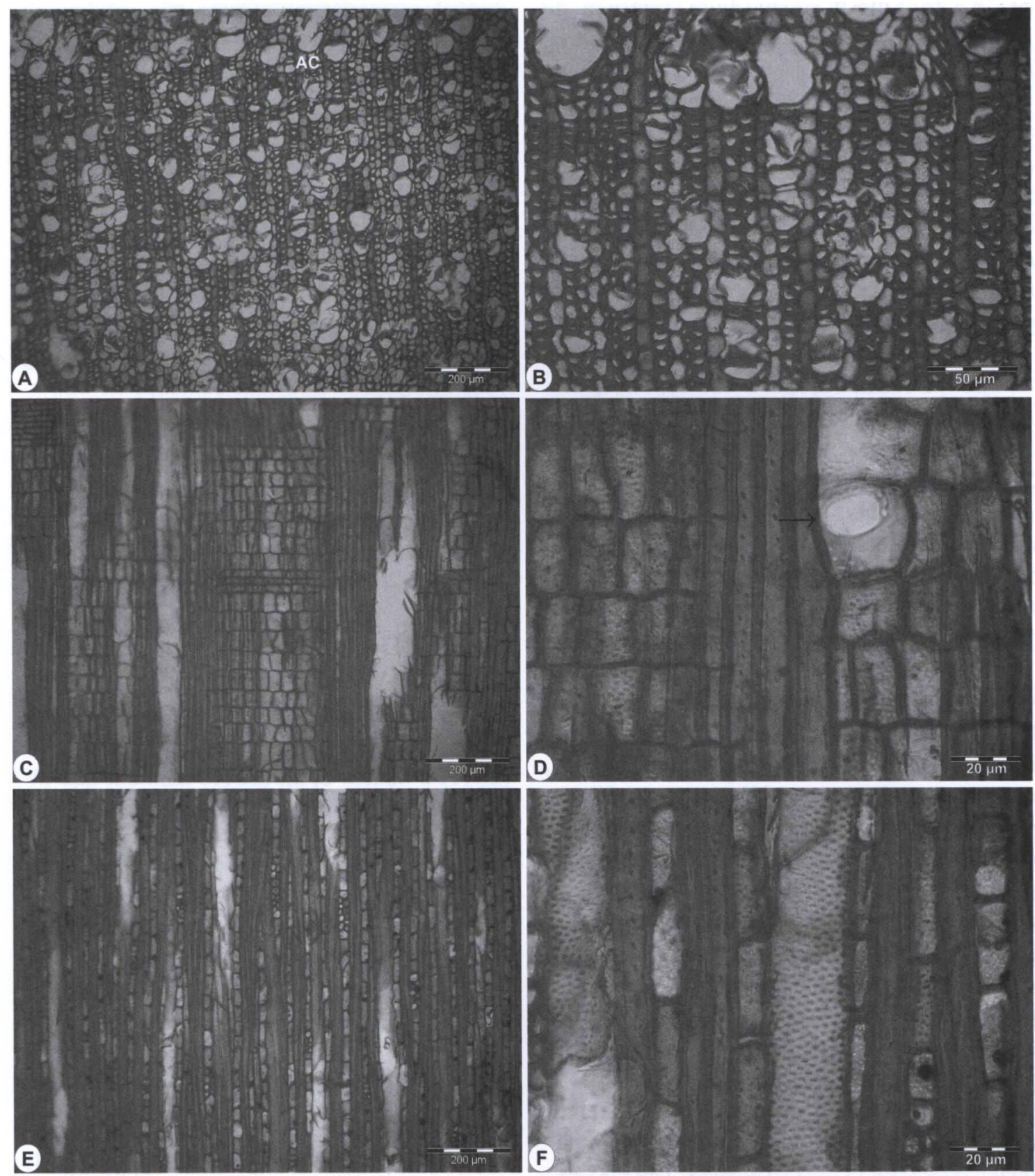

FIGURA 1 - Fotomicrografias da madeira de Cephalanthus glabratus. A - Plano transversal, mostrando porosidade semi-difusa, poros solitários, em múltiplos radiais, e limite de anel de crescimento (AC). B - Mesma seção, com maior aumento, destacando fibras de paredes finas a espessas, achatadas ao final do lenho tardio, e parênquima apotraqueal difuso. C - Raio heterogêneo, com células procumbentes, quadradas e eretas (seção longitudinal radial). D - Célula perfurada de raio (seta), em seção longitudinal radial. E - Seção longitudinal tangencial, com raios uni e bisseriados, muito altos $(>1 \mathrm{~mm})$ e de largura constante. $\mathrm{F}$ - Vasos com pontoações intervasculares alternas e fibras com pontoações areoladas (seção longitudinal tangencial). 
tadas; e raios heterogêneos. Algumas diferenças no tocante à porosidade, arranjo do parênquima axial e diâmetro de poros foram, todavia, observadas.

Koek-Noorman (1970) encontrou porosidade em anel em Cephalanthus salicifolius e $C$. occidentalis. Record \& Hess (1949), por sua vez, também referiram o mesmo padrão de distribuição de poros para a última destas espécies. Para o gênero em estudo, entretanto, Metcalfe \& Chalk (1972) mencionam a ocorrência de porosidade semi-difusa.

No material examinado, o parênquima axial, do tipo apotraqueal difuso e paratraqueal escasso, concorda com o observado por KoekNoorman (1970), mas difere do referido por Metcalfe \& Chalk (1972), que indicam parênquima axial vasicêntrico para Cephalanthus. Record \& Hess (1949), apesar de não incluírem referências ao arranjo do parênquima no gênero em estudo, informam que na família predomina o tipo paratraqueal escasso.

Para o gênero Cephalanthus, Koek-Noorman (1970) e Metcalfe \& Chalk (1972) também referem a presença de poros com mais de $100 \mu \mathrm{m}$ de diâmetro. No material investigado, todavia, encontrou-se diâmetro médio de apenas $57 \mu \mathrm{m}$, valor bem abaixo do acima indicado. Cabe salientar que esta característica, bem como a porosidade, são fortemente influenciadas pelas condições ambientais, especialmente pela disponibilidade hídrica, provável motivo das discrepâncias observadas. Sobre este ponto, Roig (1986) observa que a porosidade semi-difusa está associada a ambientes mais úmidos e a porosidade em anel a ambientes mais secos.

Para o gênero em estudo, a literatura refere raios exclusivamente unisseriados e/ou parcialmente bisseriados (Record \& Hess, 1943; KoekNoorman, 1970; Metcalfe \& Chalk, 1972). No material investigado, cabe salientar, ocorrem apenas raios com 1 ou 2 células de largura.

A presença de ornamentações, de células perfuradas e de raios estreitos, com até $1 \mathrm{~mm}$ de altura, são os aspectos mais marcantes na anatomia de Cephalanthus glabratus. Este conjunto de caraterísticas, todavia, não constitui novidade para o gênero, sendo mencionado por todos os autores acima citados.

Como inicialmente descrito, Cephalanthus glabratus é espécie reófila e, como tal, deve contar com adaptações estruturais relacionadas a esta peculiaridade ecológica. É o caso, por exemplo, da presença de fibras longas e de raios altos e estreitos, aspectos que, segundo Eames \& McDaniels (1953), aumentam a flexibilidade do caule, característica especialmente importante no caso de plantas submetidas à correnteza das águas.

Em estudo de 4 espécies reófilas, Denardi (2007) observou uma série de características comuns, indicadoras da "síndrome anatômica de reofilia". Nem todos estes aspectos, todavia, são observados no lenho de Cephalanthus glabratus: é o caso das fibras que, embora não gelatinosas, são mais longas e ocorrem em menor freqüência do que o indicado por Denardi (2007) para a referida síndrome. Em estudo de Colliguaya brasiliensis e Ruprechtia salicifolia, espécies sabidamente reófilas, Siegloch et al. (2011) e Santos et al. (2011) também não observaram integralmente as características anatômicas referidas por Denardi (2007); tais diferenças, segundo Santos et al. (2011), podem estar vinculadas a aspectos taxonômicos.

Vale lembrar, por fim, que a ausência de fibras gelatinosas não implica, necessariamente, em menor flexibilidade do caule. $\mathrm{O}$ grande volume de tecido parenquimático (raios + parênquima axial), o baixo percentual de fibras, as fibras relativamente longas e os raios altos podem compensar, pelo menos em parte, o efeito da ausência de fibras gelatinosas na flexibilidade da madeira em estudo.

\section{REFERÊNCIAS BIBLIOGRÁFICAS}

BACIGALUPO, N.M. Rubiaceae, Rubiáceaes. In: BURKART, A. Flora Ilustrada de Entre Ríos (Argentina). Buenos Aires: I.N.T.A., 1974. v. 6. p. 3-50. 
BACKES, A.; NARDINO, M. Nomes populares $e$ científicos das plantas do Rio Grande do Sul. São Leopoldo: Editora Unisinos, 2001. 202 p.

BRUSSA SANTANDER, C.A.; GRELA GONZÁLES, I.C. Flora arbórea del Uruguay. Con énfasis en las especies de Rivera y Tacuarembó. Montevideo: Cofusa, 2007. 542 p.

BURGER, L.M.; RICHTER, H.G. Anatomia da Madeira. São Paulo: Ed. Nobel, 1991. 154 p.

CABRERA, A.L.; ZARDINI, E.M. Manual de la flora de los alrededores de Buenos Aires. Buenos Aires: ACME, 1978. 755 p.

DENARDI, L. Anatomia e flexibilidade do caule de quatro espécies lenhosas para o manejo biotécnico de cursos de água. Santa Maria: Universidade Federal de Santa Maria, 2007. 112 f. Tese de Doutorado (Programa de Pós-Graduação em Engenharia Florestal).

DUJARDIN, E. P. Eine neue Holz-Zellulosenfaerbung. Mikrokosmos, n. 53, p. 94, 1964.

EAMES, A.J.; McDANIELS, L.H. An introduction to Plant Anatomy. Bombay: New Dehli, 1953. $427 \mathrm{p}$.

KOEK-NOORMAN, J. Contribution to the wood anatomy of South American (chiefly Suriname) Rubiaceae. I. Acta Bot. Neerl., v. 18, n.1, p. 108123, 1969a.

KOEK-NOORMAN, J. A contribution to the wood anatomy of South American (chiefly Suriname) Rubiaceae. II. Acta Bot. Neerl., v.18, n.2, p. 377 395, 1969b.

KOEK-NOORMAN, J. A contribution to the wood anatomy of the Cinchoneae, Coptosapelteae and Naucleeae (Rubiaceae). Acta Bot. Neerl., v.19, n.2, p. 155-164, 1970.

KOEK-NOORMAN, J. The wood anatomy of Gardenieae, Ixoreae and Mussaendeae (Rubiaceae). Acta Bot. Neerl., v. 21, n. 3, p. 301320, 1972.

KOEK-NOORMAN, J.; HOGEWEG, P. The wood anatomy of Vanguerieae, Cinchoneae, Condamineae, and Rondeletieae (Rubiaceae). Acta Bot. Neerl. v. 23, n.5, p. 627-653, 1974.

IAWA COMMITTEE. IAWA list of microscopic features for hardwood identification. IAWA Bulletin, v.10, n. 3, p. 218-359, 1989.
JANSEN, S.; ROBBRECHT, E.; BEECKMAN, H.; SMETS, E. Wood anatomy of the predominantly African representatives of the tribe Psychotrieae (Rubiaceae-Rubioideae). IAWA Bulletin, v. 18, n. 2, p. 169-196, 1997.

JOLY, A. B. Botânica: introdução à Taxonomia Vegetal. São Paulo: Co. Edit. Nacional, 2002. 777 p. JUDD, W. S.; CAMPBELL, C. S.; KELLOGG, E. A.; STEVENS, P. F.; DONOGHUE, M. J. Sistemática vegetal: um enfoque filogenético. Porto Alegre: Artmed, 2009. p. 469-470.

LAHITTE, H. B.; HURREL, J. A. Los arboles de la isla de Martín García. Buenos Aires: Província de Buenos Aires, 1994. 135 p.

MARCHIORI, J.N.C. Comprovação da viabilidade da utilização da seção longitudinal tangencial para a determinação histométrica dos elementos axiais do xilema secundário. In: Anais do IV Congresso Florestal Estadual, Nova Prata, RS, p. 180-184, 1980.

METCALFE, CR.; CHALK, L. Anatomy of the Dicotyledons. Oxford: Clarendon Press, 1972. v. 2. p. 1092-1101.

PATEL C.R.; PATEL D.A. Occurrence and significance of cell inclusions in Rubiaceae. Curr. Bot., v. 2, n. 4, p. 6-11, 2011.

RECORD, S.J.; HESS, R.W. Timbers of the New World. New Haven: Yale University Press, 1943. p. $430-433$.

REITZ, R.; KLEIN, R.M.; REIS, A. Projeto Madeira do Rio Grande do Sul. Porto Alegre: Sudesul, 1988. 525p.

ROGERS, G. K. The genera of Rubiaceae in the Southeastern United States, part II. Subfamily Rubioideae, and subfamily Cinchonoideae revisited (Chiococca, Erithalis, and Guettarda). Harvard Papers in Botany, vol. 10, n. 1, p. 145, 2005.

ROIG, F. The wood of Adesmia horrida and its modifications by climatic conditions. IAWA Bulletin, v. 7, n. 2, 1986.

SANTOS, S.R.; SIEGLOCH, A.M.; MARCHIORI, J.N.C. Anatomia da madeira de Ruprechtia salicifolia (Cham. \& Schtdl.) C. A. Mey. (Polygonaceae). Balduinia, Santa Maria, n. 28, p.27-32, 2011. 
SCHULTZ, A.R. Introdução ao estudo da Botânica Sistemática. Porto Alegre: Globo, 1963, 426 p. SIEGLOCH, A.M.; SANTOS, S.R. dos; MARCHIORI, J.N.C. Estudo anatômico do lenho de Colliguaya brasiliensis Klotzsch ex Baill. (Euphorbiaceae). Balduinia. Santa Maria. n. 27, p. 27-33, 2011.

SOBRAL, M.; JARENKOW, A.; BRACK, P.; IRGANG, B.; LAROCCA, J.; RODRIGUES, R.S. Flora arbórea e arborescente do Rio Grande do Sul. São Carlos: RiMa: Novo Ambiente, 2006. p. 142-143. 